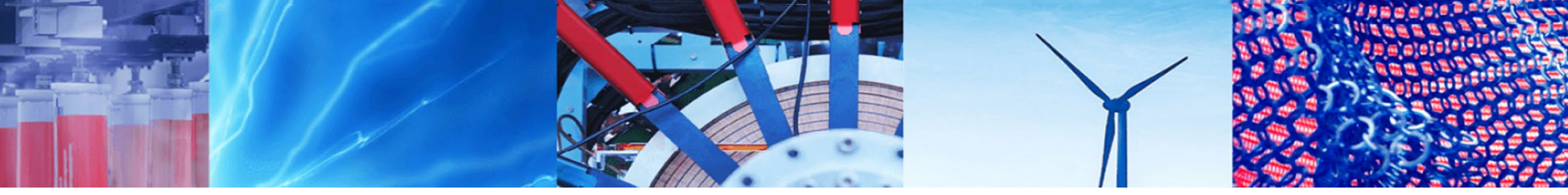

Review Paper

\title{
A review on hazards and their consequences in firework industries
}

\author{
S. Ajith ${ }^{1} \cdot$ C. Sivapragasam ${ }^{1} \cdot$ V. Arumugaprabu ${ }^{2}$
}

(c) Springer Nature Switzerland AG 2018

\begin{abstract}
Most of the firework products that India consumes are manufactured from Sivakasi, a town in Virudhunagar district in the state of Tamil Nadu. The manufacturing process in the firework industries involves manual handling of various chemicals. Hence firework industries are known to be highly hazardous. The aim of this article is to review the hazards involved in the firework industries, causes for accidents and effects of fireworks in air quality. Majority of the previous studies focussed on unsafe acts and unsafe conditions and reported that human error was the major reason for the accident to occur. But there was no proven research that the firework accidents were only due to human error. In addition to this, risk assessment plays a vital role to mitigate accidents. So in order to evaluate the hazards in firework industries, Risk Assessment for Safety and Health and Chemical Health Risk Assessment techniques can be adopted as they are associated with both safety and health risk. Hence from this review study it was observed that, conducting risk assessment and identifying the probable human error in each process will prevent further accidents.
\end{abstract}

Keywords Firework industry $\cdot$ Accident $\cdot$ Safety $\cdot$ Risk $\cdot$ Human error

\section{Introduction}

Industrial development is essential for any developing nation. In India, firework industries possess an overwhelming position in the industrial improvement of the nation. It gives large number of employment to the people in and around Sivakasi, Tamil Nadu [1]. As there is dry climate in this area throughout the year, it is most suitable for manufacturing firework products. These industries supplies sparklers and crackers for all festivals [2]. Firework products are used world-wide during cultural and national celebrations [3]. Around $90 \%$ of the India's firework manufactures are from Sivakasi, in which ladies are employed in large numbers. As the industries are mostly situated in rural areas, the people working in these industries are almost illiterate. Each and every work is done manually but still the workers are unaware of handling the chemicals. Hence the accident rate is high when compared to other industries [4]. Workers should be trained to understand about Material Safety Data Sheets (MSDS) which can be a guide for handling the chemicals. Metallic tools must be avoided while handling chemicals [5]. Even the accident rate is high, these industries rehabilitate as soon and it fulfils ninety percentage of the worldwide requirement of firework products. Thus Sivakasi is known as "Mini Japan" (Kutty Japan) [6]. To maintain safety in chemical handling, industries an efficient hazard analysis and evaluation should be done before initiating the manufacturing process. This was done to reduce the risk by adopting suitable control measures [7]. The health impacts of firework products are many such as inhalation of firework smoke leads to eosinophilic pneumonia, barium rich aerosols causes asthma, perchlorates damages thyroid glands [8] and it reduces visibility due to opaque cloud formation [9]. While reviewing the welfare facilities for the workers it was known that the management lacks in providing facilities such as maintaining baby care, recreation, schools and sports centre for their children. But drinking water facility,

\footnotetext{
$\triangle$ V. Arumugaprabu, v.arumugaprabu@klu.ac.in | ${ }^{1}$ Department of Civil Engineering, Kalasalingam Academy of Research and Education, Krishnankoil, Tamil Nadu 626126, India. ${ }^{2}$ Department of Mechanical Engineering, Kalasalingam Academy of Research and Education, Krishnankoil, Tamil Nadu 626126, India.
}

SN Applied Sciences (2019) 1:120 | https://doi.org/10.1007/s42452-018-0129-1 
lavatory, transport and insurance were well established [10]. The main aim of occupational health and safety is to protect the people form hazards in the work environment and provide suitable mitigation measures to avoid the risk that will occur in the workplace [11]. In order to achieve this, every firework industry should follow health safety procedure as mentioned in factories act and the government should take necessary steps in evaluating the industries safety policies and procedures. This review intends to report the manufacturing process, hazards and its associated risk in the firework industries and the effect of firework products in air quality.

\subsection{Process involved in firework industries}

The manufacturing process of the firework products as shown in Fig. 1 takes place in separate manufacturing shed. Each and every process involves manual handling of chemicals which is hazardous and can cause ill health to the workers. The size of the manufacturing sheds as stated in the factories act are the minimum dimensions. If the factories follow these dimensions, then the accidents occurring due to unsafe conditions can be drastically reduced and if the workers were trained for safe handling of chemicals then accidents occurring due to unsafe acts can also be reduced.

\section{Data collection}

A field visit was done in order to study the manufacturing process and the hazards involved in the firework industries. Direct observation method was done and the major findings were noted. Accident data of firework industries in Tamil Nadu was obtained from chief inspectorate of factories, Chennai and from training centre for Industrial Safety and Health, Sivakasi. The accident data as shown in Fig. 2 clearly explains that large numbers of accidents occur every year in the firework industries and Fig. 3 shows the percentage of fatality occurs in every process during the manufacture of fireworks.
Fig. 1 Process in firework industries

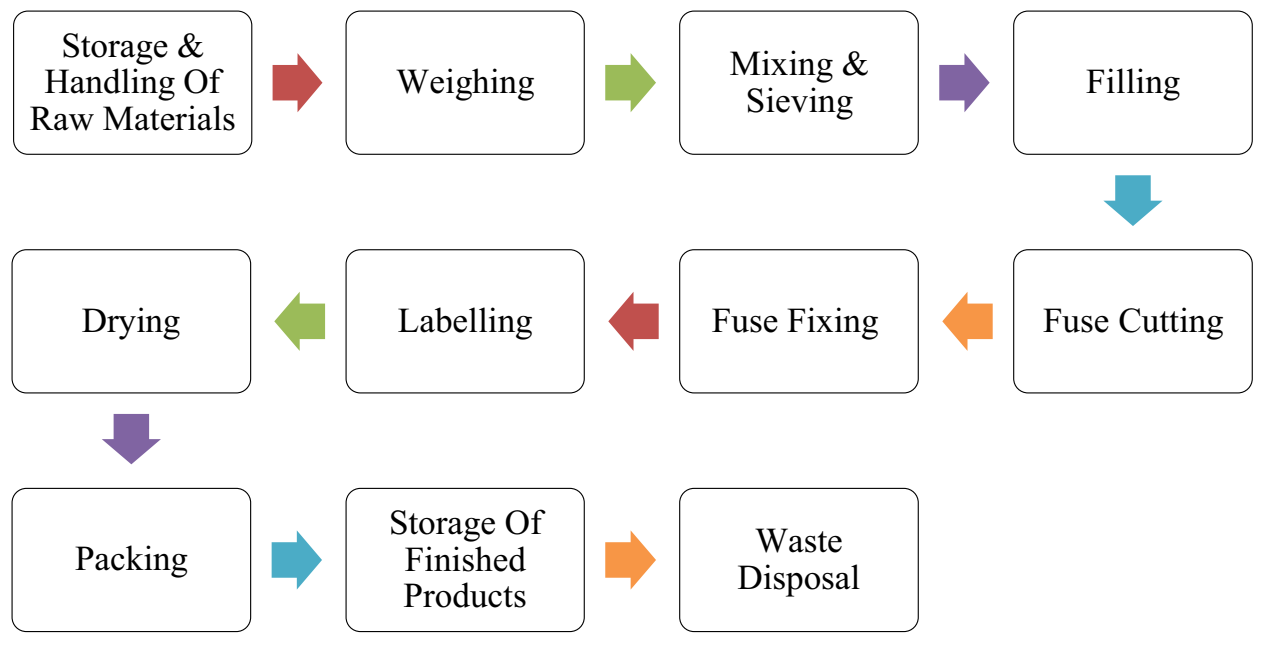

Fig. 2 No. of fatalities in firework industries

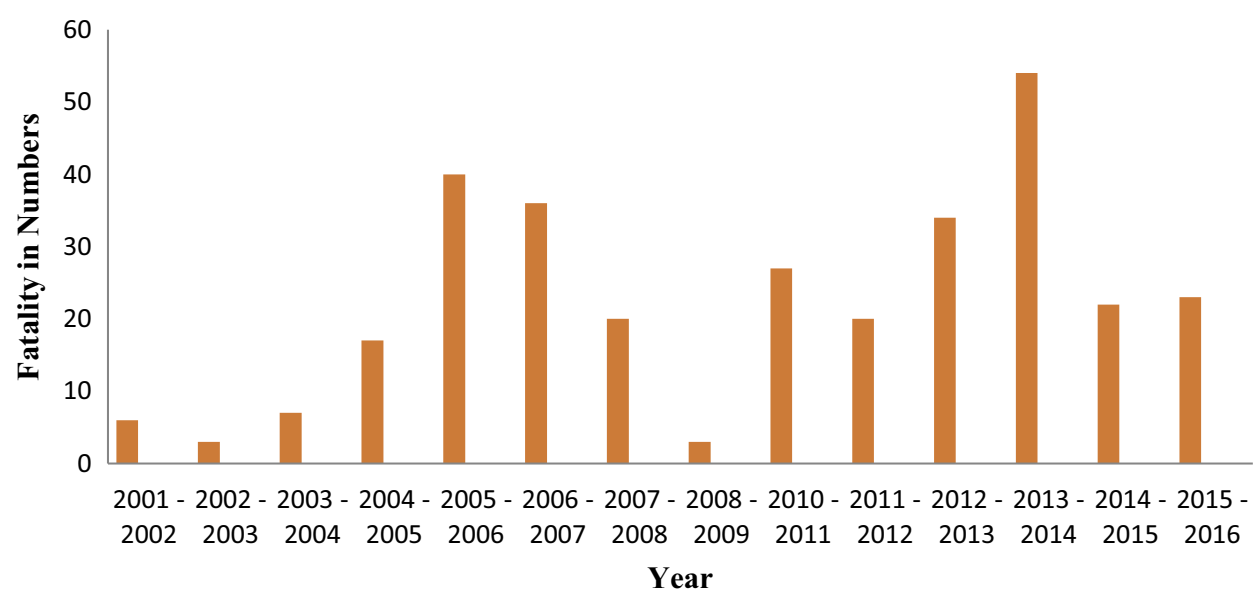




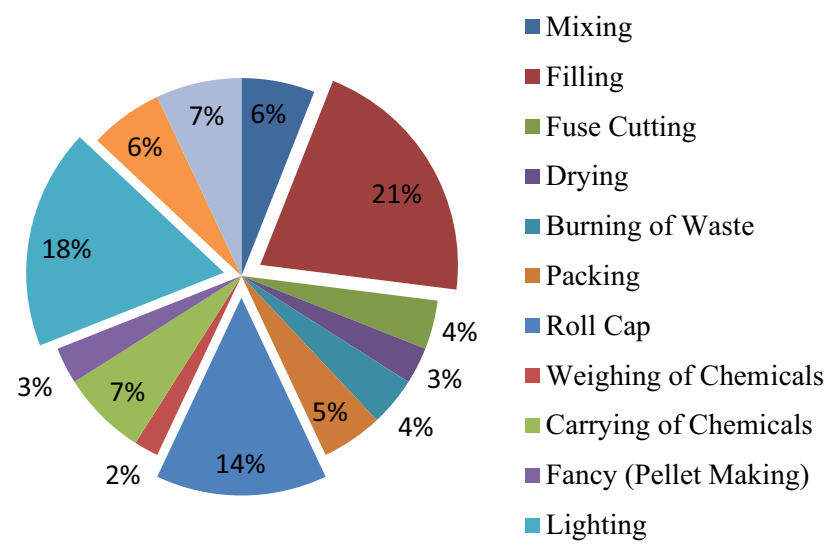

Fig. 3 Number of fatalities in each process

\section{Possible hazards of pyrotechnics}

Each and every chemical present in firework industries are hazardous in nature. Firework products are the combination of both fuel and oxidizing agent. As the workers are exposed continuously to the chemicals this may cause health effects [12]. The key hazards involved in firework industries are toxic release, fire and explosion. In this, fire is the foremost hazard which may lead to ill health to human as well as property loss [13]. Static electricity is another foremost hazard that happens in the firework industries. These types of hazards may occur when the surface of the solids and the chemicals are in contact with each other [14]. Manual blending of chemicals such as fuels, oxidizers, and igniters are done using wooden plate. The possible hazards during chemical blending are static electricity, friction, impact and human errors. During transportation of the manufactured products, activity such as careless handling, impact loading, improper stacking and dragging are the unsafe acts/human errors which cause accidents [15]. Firecrackers emits pollutants such as sulphur dioxide, carbon dioxide, carbon monoxide, nitrogen oxide and other suspended particles which can cause health related problems. While using crackers during festivals the toxicity level throughout the environment is high [16]. In order to assess the hazards involved in the firework industries Sivapirakasam et al. [17] used what-if analysis. What-if questions have been prepared for the mentioned process and it was found that impact and or friction are the major hazard which can lead to fire/explosion. Jennings-White and Kosanke [18] studied the hazardous chemical combination to reduce the effect of the hazards in industries. The general way to reduce the effect of hazard is to consume all the extra chemicals by burning. The unused chemical mixture be disposed safely immediately. This should be disposed by burning far away from the industry whereas care should be taken while transporting the unwanted chemicals as it can be ignited due to friction. Sridhar et al. [19] reported the reasons for firework accidents such as unawareness about the chemicals, lack of infrastructure, failure to maintain the floors of the manufacturing shed and lack of training.

\section{Causes for accidents}

Rajathilagam and Azhagurajan [20] analysed the causes for accidents in firework industries. Data were collected from the workers in the firework industries and analysed through factor matrix. A total of nine factors were considered such as layout of the factory, awareness on accidents, supporting aids for safety, working environment and overtime, means of escape, safe disposal and firefighting, housekeeping and training, safety counselling and environmental conditions. As a result there are five factors which shows negative loading which are awareness on accidents, supporting aids for safety, environmental conditions, housekeeping and safety and safety counselling. This clearly indicates that the accidents in the firework industries are mainly due to these five factors. Ravi and Gandhinathan [21] reported that most of the accidents occurred during the manufacturing of fancy type crackers. In this method, slurry is manufactured by the chemicals mixed with water. After the slurry was prepared it should be kept under proper ventilated area to avoid heat accumulation but when these were not taken into consideration there will be a chance for fire accidents. In another research, Sekar et al. [22] analysed the root causes for accidents by categorizing it into small, medium and large fire accidents with case studies. The reasons behind those accidents were friction, careless mistake, automatic flames, power leakage and lightning effects. Among these reasons friction plays a major role in most of the accidents. Chen et al. [23] found the causes of death for gun powder explosion in firework factory. As the gunpowder has high sensitivity it will be kept in separate manufacturing shed. When it gets exploded due to unknown sources of ignition the impact on the workers were severe with large wounds or fatality. The fatality rate due to the gun powder explosion is very high when compared to other chemicals. The causes for the firework accidents were also analysed by the government organization as shown in Fig. 4 in which $36 \%$ of the accidents reported was mainly due to friction.

\section{Analysis of safety}

To determine the safe work condition in the firework industry, Padma [24] framed a questionnaire which includes parameters such as age, sex, process, training, 


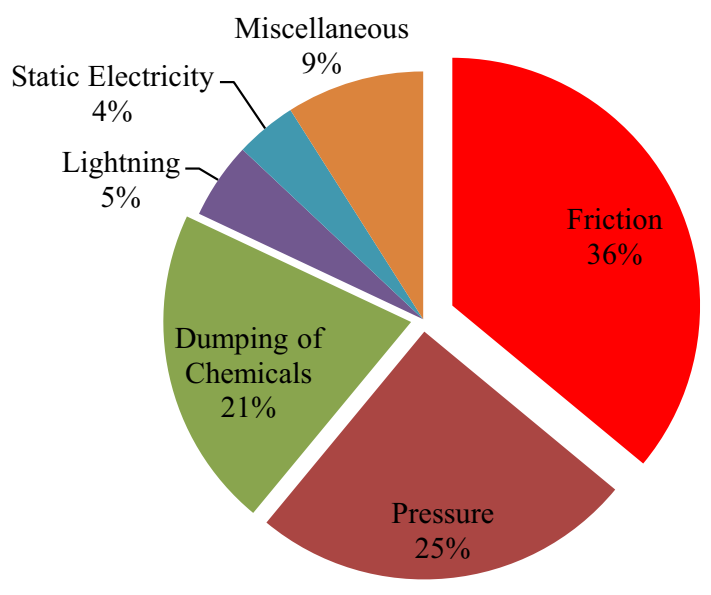

Fig. 4 Causes for accidents

awareness and health illness. The labours and management were also involved in discussion to get an idea about the industry and the surroundings. Data was collected from 171 respondents and interpreted. The results of the questionnaire showed that $89 \%$ of the labours were unaware of the hazardous chemicals and only the remaining were aware of it. In the second case $92 \%$ of the worker said that no training was provided to them before any task has to be done and $8 \%$ of people opposed this. The third case was the impact of chemicals in human health. For this $83 \%$ of the worker confirmed that they are aware of the hazardous chemicals, $12 \%$ of the worker said that there was no impact and $5 \%$ of the worker said that they have no idea. In the last case the workers were asked to answer whether the management provides safety tools during work. From the analysis it was known that $97 \%$ of the workers reported that there were no safety tools and the remaining workers said that there are safety tools.

\subsection{Chemical Health Risk Assessment (CHRA)}

To perform Chemical Health Risk Assessment (CHRA) Husin et al. [25] selected a chemical research lab where the exposure level is high. In order to calculate CHRA exposure rating (ER), the duration rating (DR) and the magnitude rating (MR) has to be determined. The duration rating was determined by qualitative observations. The least duration rating is 1 , where the exposure level is $<12.5 \%$ of the working hours. The maximum rating is 5 , where the level of exposure is $>87.5 \%$ of the working hours. Then the magnitude rating was determined using the chemicals present and absorbed by a separate rating technique. After determining the magnitude rating, the risk rating (RR) was calculated by square root of multiplying the hazard rating and exposure rating. From the assessment it was known that every department in the research lab has to pinpoint the safety measures in order to reduce the exposure.

\subsection{Risk Assessment of Safety and Health (RASH)}

Risk Assessment of Safety and Health adopts the parent risk assessment model in which this includes the health risk. This method was proposed for construction industries but it can be also used for firework industries as a general risk assessment model. As firework industries involves in handling and prolonged exposure of chemicals, RASH might be a suitable method for assessing the risk in firework industries. The combination of severity and likelihood was known as risk but RASH includes the likelihood for both safety and health and vice versa for severity [26].

\subsection{Chi square analysis}

In order to analyse the safety climate in firework industries, Rajathilagam [27] performed Chi square test with 12 hypothesis. The hypothesis was framed between the company and the contract workers. The Chi square test reveals that the comparison of the company/contract workers and the action taken against the employees does not hold good. All other hypotheses such as opinion on contract works, safety budget, level of risk, education of the respondents and firefighting checking holds good.

\section{Effect of pyrotechnics in air quality}

Firework products consists of chemicals such as barium nitrate, strontium nitrate, sodium oxalate, manganese, sulphur, charcoal, potassium perchlorate, potassium nitrate etc. When these products were burnt it creates large number of pollutants such as carbon monoxide, carbon dioxide, sulphur dioxide and metals such as manganese, aluminium, cadmium etc. When people inhale this polluted air it will cause severe health issues [28]. To assess the particulate matter, Bhatnagar and Dadhich [29] used a high volume pump which was fixed above the ground level. It consists of a filter holder in which a fibre glass filter was placed. In order to maintain stable temperature and relative humidity, the filters were kept in silica gel desiccators for $24 \mathrm{~h}$. Then sampling is done by measuring the filters using a precise scale. After the sampling was done the moistures present in the filter was absorbed again. Finally the difference in weight of the filters before and after the sampling was measured. Likewise the measure of particulates per unit volume was calculated and the contents of $\mathrm{PM}_{10}$ and $\mathrm{PM}_{2.5}$ were determined. Ultimately the concentrations of $\mathrm{PM}_{10}$ and $\mathrm{PM}_{2.5}$ were compared with EPA established National Ambient Air Quality Standards 
(NAAQS). From the results it was known that the concentration level was $400.6 \mu \mathrm{g} / \mathrm{m}^{3}$ and $121.5 \mu \mathrm{g} / \mathrm{m}^{3}$ for $\mathrm{PM}_{10}$ and $\mathrm{PM}_{2.5}$ respectively. This indicates that the concentration level was higher than the NAAQS limit. In order to determine the respirable suspended particulate matter (RSPM) and suspended particulate matter (SPM), Chauhan et al. [30] used respirable dust sampler. RSPM concentration raised up to three times in commercial and residential areas i.e. $387 \mu \mathrm{g} / \mathrm{m}^{3}$ and $312 \mu \mathrm{g} / \mathrm{m}^{3}$, whereas the values of SPM have also raised to $723 \mu \mathrm{g} / \mathrm{m}^{3}$ and $618 \mu \mathrm{g} / \mathrm{m}^{3}$ during the festival of Diwali. The results showed that the concentration level was higher than the permissible limit $(200 \mu \mathrm{g} /$ $\mathrm{m}^{3}$ and $100 \mu \mathrm{g} / \mathrm{m}^{3}$ ). Despite the fact, that effect of Diwali is short term but the short term exposure of these contaminants has ascended the RSPM and SPM values three times above the NAAQS. Likely this was the most noteworthy reason for various health problems. In addition with $\mathrm{PM}_{10}$, Barman et al. [31] conducted air quality test similar to the previous researchers to determine $\mathrm{NO}_{\mathrm{x}}, \mathrm{SO}_{2}$ and ten trace metals related with $\mathrm{PM}_{10}$ such as Calcium (Ca), Iron (Fe), Zinc ( $\mathrm{Zn})$, Copper ( $\mathrm{Cu})$, Lead $(\mathrm{Pb})$, Manganese $(\mathrm{Mn})$, Carbon monoxide (Co), Chromium (Cr), Nickel (Ni) and Cadmium (Cd). Results showed that during the night of Diwali, $\mathrm{PM}_{10}$ increased by $446.8 \%, \mathrm{SO}_{2}$ by $289.3 \%$ and $\mathrm{NO}_{\mathrm{x}}$ by $121.3 \%$. It was known that these values are higher when compared to NAAQS which was 100,80 and $80 \mu \mathrm{g} /$ $\mathrm{m}^{3}$. The concentration of $\mathrm{Cu}, \mathrm{Ni}, \mathrm{Cr}, \mathrm{Zn}$ and $\mathrm{Cd}$ in air were high when compared to other metals. Kwon [32] reported that in the eventuality of any fire or explosion, then the consequences will not limit not only to the workers but also to the residents and environment. To prevent such type of incidents every factory should follow the accident prevention system.

\section{Conclusions}

From the review the following conclusions were drawn

- Firework industries are highly hazardous when compared to all other industries. Each and every year accident occur in these industries due to unsafe acts and unsafe conditions.

- This article reviewed the manufacturing process involved in those industries, possible hazards, causes for accidents, analysis of safety using different techniques and the effect of pyrotechnics in air. There are only a few literatures that are focused to identify the root causes of accidents that occur.

- As most of the workers are illiterate, necessary safety trainings on safe work procedure, hazards of the chemicals can be thought to create awareness among the workers.
- Prioritizing the risks in various manufacturing process before an accident will help the workers to take preventive action of their own work. In addition to this human error in each process can be identified and mitigation measures can be adopted to reduce the likelihood of fatality.

- If the management provides welfare facilities, safety and health to the workers according to the legislation, then the workers may have a hazard free environment.

\section{Compliance with ethical standards}

Conflict of interest The authors declare that they have no conflict of interest.

\section{References}

1. Vijayaragavan T (2014) A study on perception of the employees relating to the job satisfaction at standard fireworks in Sivakasi. GE Int J Manag Res 2(7):363-374

2. Palaneeswari T (2012) A study on attitude of fireworks manufacturers in Sivakasi towards eco-friendly fireworks. Int J Trade Commer 1:204-212

3. Vassilia K, Eleni P, Dimitrios T (2004) Firework-related childhood injuries in Greece: a national problem. Burns 30(2):151-153

4. Rajathilagam N, Rajathilagam N, Azhagurajan A (2012) Accident analysis in fireworks industries for the past decade in Sivakasi. Int J Res Soc Sci 2(2):170-183

5. Sivaprakash P, Karthikeyan LM (2014) A study on handling of hazardous chemicals in engineering industries. APCBEE Procedia 9:187-191

6. Sekar T, Ramaswamy SN, Nampoothiri NVN (2011) Explosion resistant design of pyrotechnic facilities. Int J Recent Trends Eng Technol 3:12-16

7. Jaeger N (2001) Safety strategy against potential hazards due to the handling of powders in a blending unit. J Loss Prev Process Ind 14(2):139-151

8. Sarkar S, Khillare PS, Jyethi DS, Hasan A, Parween M (2010) Chemical speciation of respirable suspended particulate matter during a major firework festival in India. J Hazard Mater 184(1-3):321-330

9. Vecchi R, Bernardoni V, Cricchio D, D'Alessandro A, Fermo P, Lucarelli F, Valli G (2008) The impact of fireworks on airborne particles. Atmos Environ 42(6):1121-1132

10. Karunai Raghavan K, Manoharan A (2015) Information literacy on workers in match and fireworks industries scenario in Tamil Nadu: an overview. Indian J Sci 21(72):279-284

11. Porchelvi RS, Devi PJ (2015) Regression model for the people working in fire work industry-Virudhunagar district. Int J Sci Res Publ 5:1-6

12. Poulton TJ, Kosanke KL (1995) Fireworks and their hazards. Fire Eng 148(6):49-66

13. Khan Fl, Abbasi SA (1999) Major accidents in process industries and an analysis of causes and consequences. J Loss Prev Process Ind 12(5):361-378

14. Hoppe T, Jaeger N, Terry J (2000) Safe handling of combustible powders during transportation, charging, discharging and storage. J Loss Prev Process Ind 13(3-5):253-263 
15. Katoria D, Mehta D, Sehgal D (2013) S Kumar," A review of risks to workers associated with fireworks industry". Int J Environ Eng Manag 4:259-264

16. Azhagurajan A, Selvakumar N (2014) Suresh A (2014) Environment friendly manufacturing using nano scale flash powder. J Sci Ind Res 73:479-484

17. Sivapirakasam SP, Surianarayanan M, Swaminathan G (2009) Hazard assessment for the safe storage, manufacturing and handling of flash compositions. J Loss Prev Process Ind 22(2):254-256

18. Jennings-White C, Kosanke KL (1995) Hazardous chemical combinations: a discussion. J Pyrotech 2:333

19. Sridhar VP, Surianarayanan M, Sivapirakasam SP, Mandal AB (2013) Accelerating rate calorimeter studies of water-induced thermal hazards of fireworks tip mixture. J Therm Anal Calorim 112(3):1335-1341

20. Rajathilagam N, Azhagurajan A (2015) Analysis of accident causes in firework industries by factor analysis technique. Int $\mathrm{J}$ Manag Soc Sci Res (IJMSSR) 4(3):51-56

21. Ravi A, Gandhinathan R (2013) Analysis of safety climate in fireworks industries in Tamilnadu. Int J Sci Eng Res 4:760-764

22. Sekar T, Ramaswamy SN, Nampoothiri N (2010) Planning of industrial estate for fireworks industries in Sivakasi. Int J Eng Sci Technol 2(6):2207-2217

23. Chen XL, Wang YJ, Wang CR, Li SS (2002) Gunpowder explosion burns in fireworks factory: causes of death and management. Burns 28(7):655-658
24. Padma A (2014) Agile augmentation of clean air in an around fire cracker industries located villages. J Environ Sci Toxicol Food Technol 8(12):01-06

25. Husin SNH, Mohamad AB, Abdullah SRS, Anuar N (2012) Chemical health risk assessment at the chemical and biochemical engineering laboratory. Procedia Soc Behav Sci 60:300-307

26. Al-Anbari S, Khalina A, Alnuaimi A, Normariah A, Yahya A (2015) Risk Assessment of Safety and Health (RASH) for building construction. Process Saf Environ Prot 94:149-158

27. Rajathilagam N (2016) Analysis of safety in fireworks industries by Chi square analysis in Virudhunagar district of Tamilnadu. Int J Manag Soc Sci Res 5:32-37

28. Wang Y, Zhuang G, Xu C, An Z (2007) The air pollution caused by the burning of fireworks during the lantern festival in Beijing. Atmos Environ 41(2):417-431

29. Bhatnagar S, Dadhich S (2015) Assessment of the impact of fireworks on ambient air quality. Int J Res Appl Sci Eng Technol 3(IV):605-609

30. Chauhan VS, Singh B, Ganesh S, Zaidi J (2014) Status of air pollution during festival of lights (Diwali) in Jhansi. Bundelkhand region, India Asian J Sci Technol 5(3):187-191

31. Barman SC, Singh R, Negi MPS, Bhargava SK (2008) Ambient air quality of Lucknow city (India) during use of fireworks on Diwali festival. Environ Monit Assess 137(1-3):495-504

32. Kwon HM (2006) The effectiveness of process safety management (PSM) regulation for chemical industry in Korea. J Loss Prev Process Ind 19(1):13-16 